\title{
The availability of attentional resources modulates the inhibitory strength related to weakly activated priming
}

\author{
Yongchun Wang ${ }^{1,2}$ - Yonghui Wang ${ }^{1,2} \cdot$ Peng Liu $^{3}$ - Dongyang Dai ${ }^{1,2}$. \\ Meilin Di ${ }^{1,2} \cdot$ Qiang Chen ${ }^{1,2}$
}

Published online: 19 May 2016

(C) The Psychonomic Society, Inc. 2016

\begin{abstract}
The current study investigated the role of attention in inhibitory processes (the inhibitory processes described in the current study refer only to those associated with masked or flanked priming) using a mixed paradigm involving the negative compatibility effect (NCE) and object-based attention. Accumulating evidence suggests that attention can be spread more easily within the same object, which increases the availability of attentional resources, than across different objects. Accordingly, we manipulated distractor location (with primes presented in the same object versus presented in different objects) together with prime/target compatibility (compatible versus incompatible) and prime-distractor stimulus onset asynchrony (SOA, $23 \mathrm{~ms}$ vs $70 \mathrm{~ms}$ ). The aim was to investigate whether inhibitory processes related to weakly activated priming, which have been previously assumed to be automatic, depend on the availability of attentional resources. The results of Experiment 1 showed a significant NCE for the 70-ms SOA when the prime and distractor were presented in the same object (greater attentional resource availability); however, reversed NCEs were obtained for all other conditions. Experiment 2 was designed to disentangle whether the results of Experiment 1 were affected by the prime position, and the results indicated that the prime position did not
\end{abstract}

Yonghui Wang

wyonghui@snnu.edu.cn

1 School of Psychology, Shaanxi Normal University, Xi'an 710062, China

2 Shaanxi Provincial Key Laboratory of Behavior \& Cognitive Neuroscience, Xi' an 710062, China

3 School of Public Management, Northwest University, Xi'an 710069, China modulate the NCE in Experiment 1. Together, these results are consistent with the claim that the availability of attentional resources modulates the inhibitory strength related to weakly activated priming. Specifically, if attentional resources are assigned to the distractor when it is presented in the same object as the prime, the strength of the inhibition elicited by the distractor may increase and reverse the activation elicited by the prime, which could lead to a significant NCE.

Keywords Negative compatibility effect · Inhibitory processes $\cdot$ Attentional spreading

\section{Introduction}

A significant number of studies have shown that inhibitory processing plays an important role in human behavior. Different tasks, such as the negative priming task, Stroop task, inhibition of return task, and masked prime task, may reflect different inhibitory processes. In the current study, we focused on the inhibitory processes associated with the masked prime task. Eimer and Schlaghecken (1998) found a typical inhibition-related effect, the negative compatibility effect (NCE), using the masked prime paradigm. In their study, a prime, such as a double-headed arrow pointing left or right, was first presented in the center of a screen for a brief period (typically less than $35 \mathrm{~ms}$ ). Second, a pattern mask, such as a superimposition of two oriented primes, was presented at the prime's location for approximately $100 \mathrm{~ms}$. Finally, a target was presented for $100 \mathrm{~ms}$. Participants were asked to use their left or right hand to correspondingly respond to the target's direction as quickly and accurately as possible. A typical NCE finding is that viewers' responses to the target are faster (and more accurate) when the target is preceded by an incompatible prime (i.e., cueing a response opposite to that indicated by the 
target), and slower (and less accurate) when a target is preceded by a compatible prime (i.e., cueing the same response as the target). The NCE reverses a positive compatibility effect (PCE) - a phenomenon whereby reactions to targets are faster when they are preceded by compatible primes, and delayed when they are preceded by incompatible primes. The PCE is observed following a very short stimulus onset asynchrony (SOA) between the prime and the target (60 ms or less, see Schlaghecken \& Eimer, 2000), or a very long SOA between the prime and the target $(500 \mathrm{~ms}$ or more, see Sumner \& Brandwood, 2008). Importantly, the electrophysiological results of Eimer and Schlaghecken (1998) showed a specific sequence of movement-related lateralized readiness potential (LRP) modulations. These latter authors observed that the LRP had different tendencies at different time periods following prime onset. At first, approximately $200 \mathrm{~ms}$ following prime onset, the LRP showed an initial tendency to prepare the response indicated by the prime. This primed response tendency activated the correct response readiness relative to the upcoming target for compatible trials, whereas it overlapped with the incorrect response readiness for incompatible trials. Crucially, approximately $350 \mathrm{~ms}$ following prime onset, the LRP signal reversed, resulting in an inhibited primed response, and a disinhibited opposite response. Overall, the LRP signal and behavioral evidence have been used to build the case for automatically triggered inhibitory control.

Originally, Eimer and Schlaghecken (1998) developed a self-inhibition (SI) hypothesis to explain the NCE based on electrophysiological and behavioral results. These authors hypothesized that motor activation by a subliminal prime is automatic, and produces inhibition that counteracts the initial activation (Eimer \& Schlaghecken, 1998, 2002; Schlaghecken \& Eimer, 2002, 2004, 2006). According to the SI hypothesis, the prime automatically activates the motor mechanisms associated with it, although the appearance of the mask removes the prime-induced perceptual evidence, which, in turn, leads to the automatic inhibition of the initial motor activation (Bowman, Schlaghecken, \& Eimer, 2006). If a compatible target is subsequently presented, the required response is still inhibited, resulting in performance costs, i.e., the NCE. Therefore, according to the SI hypothesis, the NCE reflects a low-level and automatic process of inhibitory motor control (Schlaghecken, Rowley, Sembi, Simmons, \& Whitcomb, 2007).

An alternative view of the NCE inhibitory mechanism was suggested by Jaśkowski and colleagues (Jaśkowski, 2007, 2008a, b, 2009; Jaśkowski, Białuńska, Tomanek, \& Verleger, 2008; Jaśkowski \& Przekoracka-Krawczyk, 2005; Jaśkowski \& Slósarek, 2007; Jaśkowski \& Verleger, 2007; Verleger, Jaśkowski, Aydemir, van der Lubbe, \& Groen, 2004), who proposed the mask-triggered inhibition (MTI) hypothesis. This hypothesis assumes that perceptual interactions between the prime and the mask can produce inverse priming effects. Specifically, the sudden onset of a stimulus after the prime (i.e., the mask or distractor), which results in the automatic initiation of a response preparation for the opposite arrow, interrupts the response preparation for the initial arrow; that is to say, such a sudden onset triggers an automatic inhibition of the ongoing action and possibly an activation of the alternative response. Additionally, Lleras and Enns (2006) supplied an inhibitory mechanism for their object updating (OU) hypothesis. ${ }^{1}$ The abrupt onset of a new object (the mask or distractor) will sharply reduce the activation initiated by the prime, regardless of whether or not the object is similar to the prime. Essentially, inhibition is automatically triggered by the mask or distractor. This supplemented version of the OU hypothesis was termed the OU+ hypothesis by Jaśkowski (2008a, b). With the addition of this non-specific inhibitory mechanism, the OU hypothesis becomes indistinguishable from the MTI hypothesis (Jaśkowski, 2007, 2008a, b).

Both studies of the NCE and other studies have suggested that inhibitory processes are usually automatic and do not require attention, regardless of their involvement in subliminal masked priming (i.e., unconscious priming; see, Eimer \& Schlaghecken, 1998, 2002; Eysenck, 1984; Ohman \& Soares, 1994; Ocampo \& Finkbeiner, 2013; Posner \& Snyder, 1975; Schlaghecken et al., 2007; Schneider \& Shiffrin, 1977), of the presence of flanked priming (i.e., weakly activated priming, which is elicited by the presentation of primes for a relatively short time (e.g., $50 \mathrm{~ms}$ or $20 \mathrm{~ms}$ ) followed by the presentation of distractors or short masks (e.g., $80 \mathrm{~ms}$ or $50 \mathrm{~ms}$ in Wang, Zhao, Liu, Wei, \& Di, 2014); see, Bennett, Lleras, Oriet, \& Enns, 2007; Jaśkowski, 2007, 2008a, b, 2009; Jaśkowski et al., 2008; Jaśkowski \& Verleger, 2007; Lleras \& Enns, 2006), or even of the absence of backward masking (i.e., relatively strong activated priming; see, Vainio, 2009, 2011; Vainio \& Mustonen, 2011). In particular, Vainio (2011) suggested that when motor activation is triggered by naturalistic objects, it can be automatically inhibited in the absence of backward masking, even when the object does not contain any task-relevant features.

However, although the proposal that inhibitory processes are automatic is consistent with the available data, an important factor in the methodology of these experiments might be overlooked. This factor is the time of target occurrence, which, when investigated in detail, suggests to us a different understanding of the inhibitory mechanism. The majority of these studies fixed the time of target occurrence; the subjects

\footnotetext{
${ }^{1}$ The object updating (OU) hypothesis developed by Lleras and Enns (2004) states the NCE results from the object updating that is automatically triggered by the perceptual interaction between a prime and a mask. Theoretically, the masks involved in updating should be relevant, such as stimuli that share features with the prime (e.g., an overlay of two prime types). Therefore, updating features, including features that indicate a direction opposite to that of the prime, should improve a participant's response to a target for which the direction is opposite that of the prime.
} 
could thus focus their attention on the predicted time of target occurrence and open a temporal window of attention. Therefore, the processing of primes and masks that are presented during this attentional window is benefited (see Naccache, Blandin, \& Dehaene, 2002), and thus the inhibitory processes may have received more attentional resources in these studies. As Naccache et al., (2002) demonstrated in a number-comparison task, the allocation of temporal attention to the time window during which the prime-target pair is presented determines whether unconscious priming occurs. The experiments of Naccache et al., (2002) showed that reliable priming only occurred when the target onset was fixed rather than variable. The authors considered that predicting the occurrence of targets would be more difficult in the variabletarget condition because the subjects might allocate less attention to the prime-target pair in this condition than in the fixedtarget condition. Additionally, many other studies have also manifested that attention can affect unconscious processes (Dehaene et al., 1998; Dehaene, Changeux, Naccache, Sackur, \& Sergent, 2006; Kentridge, Heywood, \& Weiskrantz, 1999; Kiefer \& Brendel, 2006; Lachter, Forster, \& Ruthruff, 2000; Neely \& Kahan, 2001; Smith, Besner, \& Miyoshi, 1994; Sumner, Tsai, Yu, \& Nachev, 2006).

This perspective is also corroborated by many research findings confirming that an NCE is obtained only at relatively short prime-target intervals and recovered to positive priming at longer intervals (e.g., Lingnau \& Vorberg, 2005; Schlaghecken \& Maylor, 2005; Sumner et al., 2007; Sumner $\&$ Brandwood, 2008). For example, Sumner and Brandwood (2008) observed NCEs when prime-target intervals were $150 \mathrm{~ms}$ and $300 \mathrm{~ms}$, but the NCE reverted to a PCE at an interval of approximately $500 \mathrm{~ms}$ (the intervals were fixed in each block in their experiments). This is probably because primes and masks that are presented at relatively close temporal intervals to the targets may benefit more from the focused attention than those presented at relatively distant temporal intervals to the targets, resulting in stronger inhibition.

Although some studies (e.g., Boy, Clarke, \& Sumner, 2008; Schlaghecken \& Eimer, 2002; Sumner et al., 2006) have indirectly suggested that the inhibitory processes related to the NCE depend on the availability of attentional resources, there is very little direct evidence for this hypothesis. The present study aimed to directly verify the effect of attention on inhibitory processes. We hypothesized that inhibitory processes previously assumed to be automatic may depend on the availability of attentional resources.

To test this hypothesis, we adopted a mixed paradigm involving the NCE and object-based attention (Fig. 1). This paradigm involved attentional spreading (Chen \& Cave, 2006, 2008; Desimone \& Duncan, 1995; Ho, 2011; Richard, Lee, \& Vecera, 2008), which suggests that attending to an object guided by a spatial cue or task instructions involves spreading attention across the entire object. This spread of

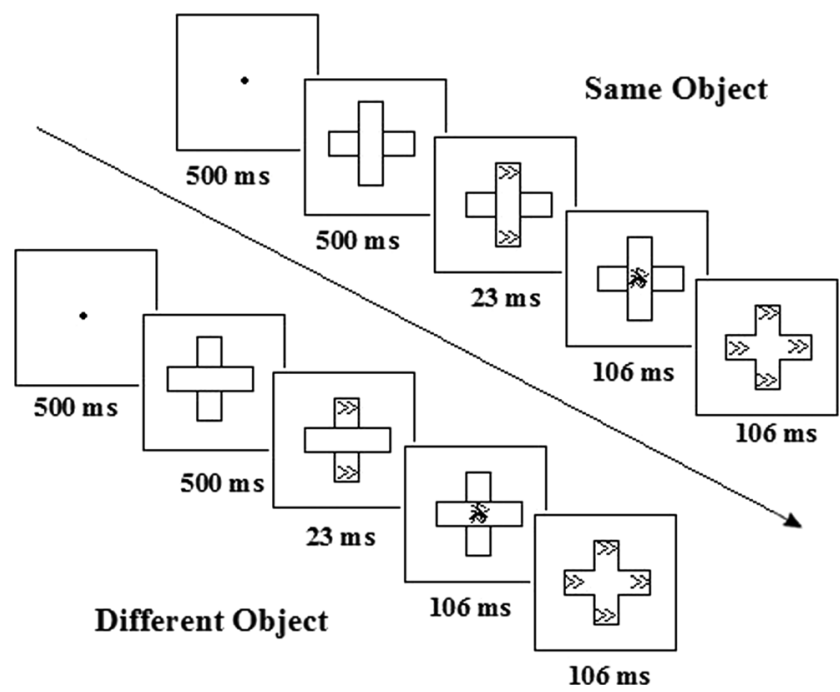

Fig. 1 Schematic representation of the trial procedure in Experiment 1

attention is limited by the contours and boundaries of the attended object (Desimone \& Duncan, 1995; Moore \& Fulton, 2005). Consequently, targets that appear on an attended object are processed more rapidly and accurately than targets that appear elsewhere because attention is more readily spread within objects than across objects (Zhao, Kong, \& Wang, 2013). This argument can explain why subjects respond faster when redirecting their attention to the same object than when redirecting their attention to another object. This phenomenon is referred to as the object-based effect (Chen \& Cave, 2006; Chou \& Yeh, 2012; Duncan, Humphreys, \& Ward, 1997; Egly, Driver, \& Rafal, 1994; Ho, 2011; Mozer \& Vecera, 2005; Zemel, Behrmann, Mozer, \& Bavelier, 2002; Zhao et al., 2013). Furthermore, the spreading of attention from a cued location to another location within the same object is time-consuming (e.g., Eriksen \& St. James, 1986; Eriksen \& Yeh, 1985; Lamy \& Egeth, 2002). For example, Lamy and Egeth (2002) found that the object-based benefit was significantly larger with a longer cue-target SOA than with a shorter SOA.

The present study was carried out under a weakly activated priming condition because, in this mixed paradigm, a nonmasking distractor was employed. Numerous studies (Dehaene et al., 1998, 2006; Kentridge et al., 1999; Kiefer \& Brendel, 2006; Lachter et al., 2000; Naccache et al., 2002; Neely \& Kahan, 2001; Smith et al., 1994; Sumner et al. 2006) have demonstrated that attention can affect unconscious processes; it was speculated that attention should also be able to modulate processes related to weakly activated priming. To be precise, in this study, we determined whether the availability of attentional resources (between the onset of the prime and the offset of the distractor) modulates the inhibitory strength related to weakly activated priming. In the task of the present study, arrow stimuli were used as primes 
and targets, and distractors were constructed from randomly distributed oblique lines of different lengths. These stimuli were presented in different positions by superimposing vertically and horizontally oriented rectangles. Specifically, in the experiments, we manipulated the SOA ( 23 or $70 \mathrm{~ms}$ ) between the primes and distractors, the compatibility of the primes with the targets (compatible versus incompatible) and the distractor locations (presented in the same object with primes versus presented in different objects). According to the attentional spreading view, when the primes and distractors are located within the same object, the availability of attentional resources will be substantially greater than that when they are located within different objects. Correspondingly, if inhibitory processes related to weakly activated priming are modulated by the availability of attentional resources, we predict that a significantly greater NCE would be observed under the same-object condition, and a substantially smaller NCE or a PCE would occur under the differentobject condition. Because the availability of attentional resources should be substantially decreased under the different-object condition, the inhibition should be substantially weaker. Furthermore, NCEs under the sameobject condition should be smaller or even disappear with a shorter SOA. This phenomenon occurs because the process by which attention spreads within an object is time consuming.

\section{Experiment 1}

\section{Method}

\section{Participants}

A total of 17 college students ( 7 male) ranging in age from 18 years to 26 years (mean age $=21.51$ years) were compensated to participate in the experiment. All of the participants were right handed and had normal or corrected-to-normal vision.

\section{Stimuli and apparatus}

Two rectangles with a visual angle of $2.4^{\circ} \times 5.2^{\circ}$ were oriented vertically and horizontally, and then superimposed. Leftand right-pointing double arrows within the superimposed rectangles were used as primes and targets, and each arrow subtended a visual angle of $1^{\circ} \times 0.35^{\circ}$. Next, distractors were constructed from randomly distributed oblique lines of different lengths. The distractors subtended a visual angle of $2.4^{\circ} \times$ $1.9^{\circ}$. All of the stimuli were black upon a white background. The experiment was performed on a $\mathrm{PC}$ running at $85 \mathrm{~Hz}$ linked to a 17 -inch CRT monitor.

\section{Procedure}

The participants were seated in a dimly lit room, and a computer screen was placed $60 \mathrm{~cm}$ in front of their eyes. The center of the screen was located in the center of their horizontal field of view.

The experimental procedure is shown in Fig. 1. Each trial began with a central fixation dot $(500 \mathrm{~ms})$. Next, vertically and horizontally oriented rectangles were superimposed, with the rectangles appearing throughout each trial. After the rectangles were present for a total of $500 \mathrm{~ms}$, a prime (doubleheaded arrow pointing left or right) was shown $(23 \mathrm{~ms})$ in both the upper and lower halves of the screen, followed by a distractor $(106 \mathrm{~ms})$. The distractor was presented either immediately upon fixation or after $47 \mathrm{~ms}$; thus, the prime distractor SOA was either $23 \mathrm{~ms}$ or $70 \mathrm{~ms}$. Finally, a target was presented for $106 \mathrm{~ms}$ within each of the four ends of the superimposed rectangles. The participants were instructed to maintain central eye fixation and respond as quickly and accurately as possible to the final arrow stimuli presented during each trial. All of the participants were instructed to use the index finger of their left hand to press the $\mathrm{Z}$ key in response to a leftpointing arrow $(<<)$ and to use the index finger of their right hand to press the M key in response to a right-pointing arrow (>>). The experiment consisted of 5 blocks with 96 trials per block. During compatible trials, the prime and target arrows were pointed in the same direction, whereas during incompatible trials, the arrows were pointed in opposite directions. All conditions $(2 \mathrm{SOA} \times 2$ compatibility $\times 2$ distractor location) were equiprobable and randomized within each block. The inter-trial interval (ITI) was $800 \mathrm{~ms}$. A 30-trial practice block was presented to each participant prior to the formal experiment, and the formal experiment did not begin until the correct response rate during the practice block exceeded $90 \%$. The participants were allowed a break of at least $2 \mathrm{~min}$ after each block, and encouraged to take longer breaks if necessary.

\section{Results}

The response times (RTs) for correct responses and the number of errors were analyzed. Two $2 \times 2 \times 2$ repeated measures analyses of variance (ANOVAs) were conducted and included the SOA (23 ms and $70 \mathrm{~ms}$ ), distractor location (same object and different object) and compatibility (compatible and incompatible). The mean RTs and mean error rates for each condition are shown in Figs. 2, 3, 4, and 5.

With respect to the RT, significant difference was not observed between the distractor locations $[\mathrm{F}(1,16)=0.75, P=$ $0.40]$ or between SOA conditions $[\mathrm{F}(1,16)=1.53, P=0.23]$. However, significant difference was observed between the compatible and incompatible trials $[\mathrm{F}(1,16)=5.22, P=$ $\left.0.036, \eta^{2}=0.25\right]$, showing that the mean RT for the compatible trials $(\mathrm{M}=384 \mathrm{~ms})$ was shorter than that for the 


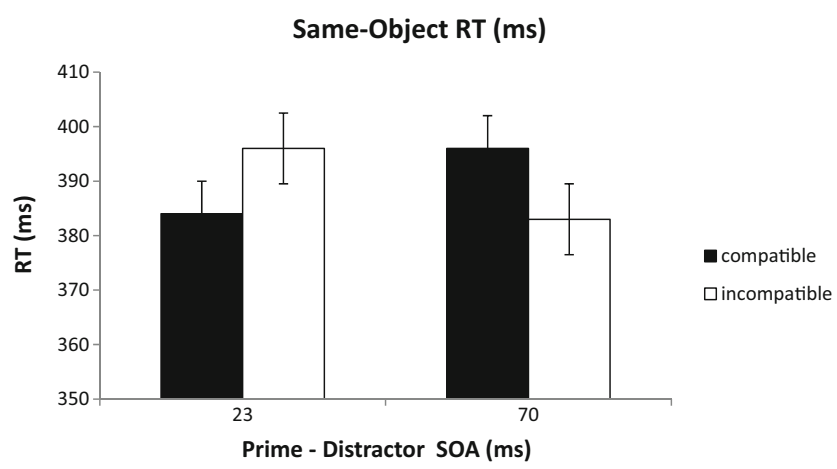

Fig. 2 Mean response times (RTs) obtained for the two stimulus onset asynchrony (SOA) conditions ( $23 \mathrm{~ms}$ and $70 \mathrm{~ms}$ ) for the compatible and incompatible trials of the same-object condition. Error bars One standard error of the mean (SE)

incompatible trials $(\mathrm{M}=394 \mathrm{~ms})$. More importantly, our analysis revealed a significant three-way interaction $[\mathrm{F}(2,16)=$ $\left.8.75, P=0.009, \eta^{2}=0.35\right]$ between the three analyzed variables and demonstrated that two-way interactions were significant for SOA $\times$ distractor location $[\mathrm{F}(1,16)=8.08, P=0.01$, $\left.\eta^{2}=0.34\right]$ and distractor location $\times$ compatibility $[\mathrm{F}(1,16)=$ $\left.4.52, P=0.049, \eta^{2}=0.22\right]$. However, the two-way interaction between SOA and compatibility was not significant $[\mathrm{F}(1,16)$ $=3.09, P=0.098]$. We then assessed the interaction between SOA and compatibility separately based on the distractor location. Figures 2 and 3 show this relationship across the two distractor locations. Under the same-object condition (Fig. 2), the two-way interaction between SOA and compatibility was significant $\left[\mathrm{F}(1,16)=6.35, P=0.026, \eta^{2}=0.43\right]$. Subsequent paired $t$-tests confirmed the presence of a highly significant $\mathrm{NCE}$ for the $70 \mathrm{~ms}$ condition $[t(16)=7.49, P=0.003]$, showing that the mean RT for the incompatible trials $(\mathrm{M}=$ $383 \mathrm{~ms}$ ) was shorter than that for the compatible trials $(\mathrm{M}=$ $396 \mathrm{~ms}$ ). However, a PCE was observed for the $23 \mathrm{~ms}$ condition $[t(16)=6.95, P=0.015]$, showing that the mean RT for the compatible trials $(\mathrm{M}=384 \mathrm{~ms})$ was shorter than that for the incompatible trials $(\mathrm{M}=396 \mathrm{~ms})$. Under the differentobject condition (Fig. 3), the two-way interaction between

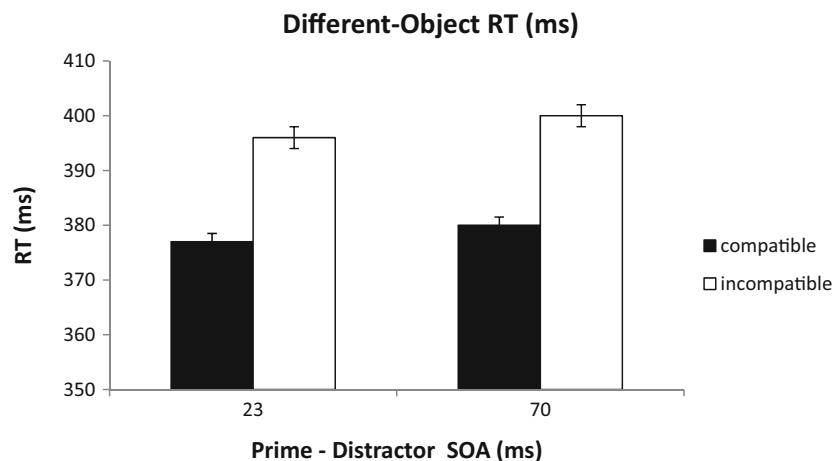

Fig. 3 Mean RTs obtained for the two SOA conditions $(23 \mathrm{~ms}$ and $70 \mathrm{~ms}$ ) for the compatible and incompatible trials of the different-object condition. Error bars $1 \mathrm{SE}$

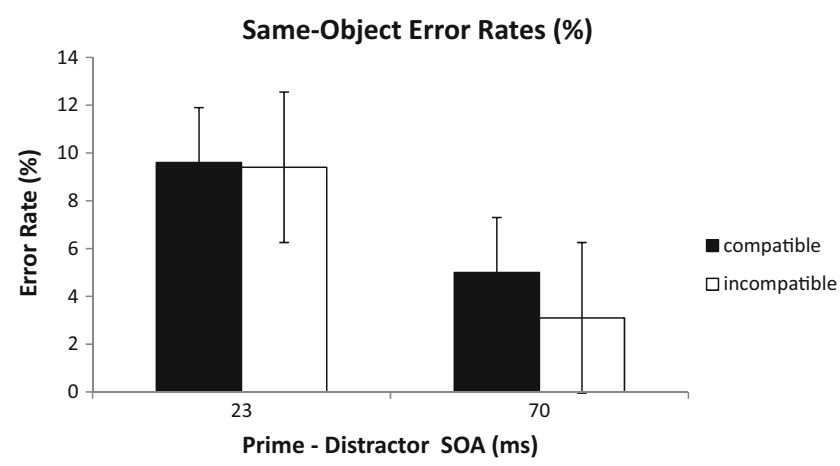

Fig. 4 Mean error rates obtained for the two SOA conditions (23 ms and $70 \mathrm{~ms}$ ) for the compatible and incompatible trials of the same-object condition. Error bars $1 \mathrm{SE}$

SOA and compatibility was not significant $[\mathrm{F}(1,16)=$ $0.002, P=0.96]$; however, a significant main effect of compatibility was observed $\left[\mathrm{F}(1,16)=9.98, P=0.001, \eta^{2}=\right.$ $0.76]$. Paired $t$-tests confirmed that a PCE was observed for the $23 \mathrm{~ms}$ condition $[t(16)=7.35, P=0.01]$, showing that the mean RT for the compatible trials $(\mathrm{M}=377 \mathrm{~ms})$ was shorter than that for the incompatible trials $(\mathrm{M}=396 \mathrm{~ms})$, as well as the $70 \mathrm{~ms}$ condition $[t(16)=7.41, P=0.009]$, showing that the mean RT for the compatible trials $(\mathrm{M}=380 \mathrm{~ms})$ was shorter than that for the incompatible trials $(M=400 \mathrm{~ms})$.

With respect to the error rate, no significant difference was observed between compatible and incompatible trials [F (1, $16)=1.71, P=0.21]$ or between the SOA conditions $[\mathrm{F}(1,16)$ $=1.41, P=0.25]$. However, a significant difference was observed between the distractor locations $[\mathrm{F}(1,16)=4.32, P=$ $\left.0.036, \eta^{2}=0.31\right]$. No significant two-way interactions were observed.

\section{Discussion}

The aim of the current experiment was to determine whether the availability of attentional resources modulates the inhibitory strength related to weakly activated priming. The results

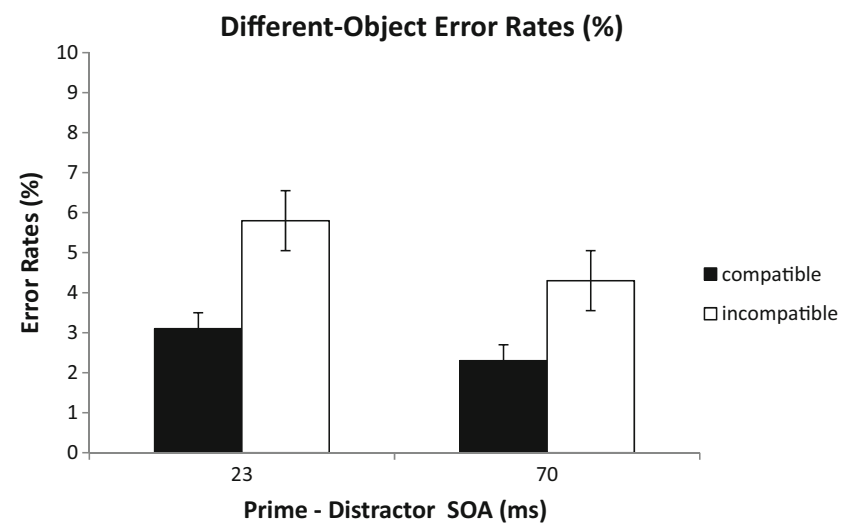

Fig. 5 Mean error rates obtained for the two SOA conditions (23 and $70 \mathrm{~ms}$ ) for the compatible and incompatible trials of the different-object condition. Error bars $1 \mathrm{SE}$ 
indicated that a significant NCE was obtained with the sameobject condition utilizing an SOA of $70 \mathrm{~ms}$, whereas a PCE was obtained for the different-object condition. In addition, a PCE was observed under the same-object conditions when the prime-distractor SOA was $23 \mathrm{~ms}$. Overall, these results indicated a primary role for the availability of attentional resources in inhibitory processes related to weakly activated priming. Specifically, these results are consistent with the claim that the improved availability of attentional resources (i.e., under the same-object condition for the 70-ms SOA) can trigger stronger inhibition, which is then capable of overcoming the prime-related motor activation, resulting in the NCE.

Nevertheless, one might argue that these effects were caused by the position of the prime. For the same-object condition, the prime was in the foreground object, which may have enhanced the strength of the prime activation. However, for the different-object condition, the prime was in the background object, which may have weakened the prime activation strength. If the prime activation strength is stronger for the former condition than for the latter condition, the availability of attentional resources could completely confound the prime position (whether in the background or the foreground object), thus making it impossible to determine which of these two factors modulates the priming effect. Therefore, appropriate control conditions are required to disentangle these factors. Experiment 2 was designed to achieve this aim.

\section{Experiment 2}

In Experiment 2, four smaller distractors were presented between the 'arms' of the crossing objects, near the center but always outside of any object-based attentional spreading (Fig. 6), and prime position (foreground versus background)

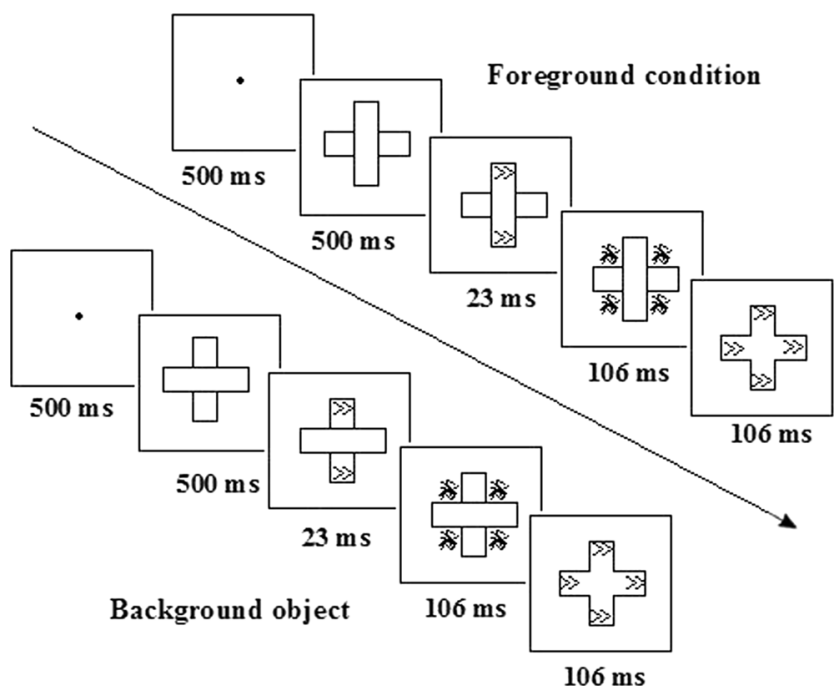

Fig. 6 Schematic representation of the trial procedure in Experiment 2 was manipulated. If the prime position modulates the prime activation strength, we predicted that a PCE would be obtained for the background condition and that an NCE or a decreased PCE would be obtained for the foreground condition. However, if the prime position does not affect the prime activation strength, then PCEs should be obtained regardless of whether the primes appear in the foreground or background object, because the distractors are presented outside of any object-based attentional spreading.

\section{Participants}

A total of 17 college students ( 8 males) ranging in age from 18 years to 29 years (mean age $=24.17$ years) were compensated to participate in the experiment. All of the participants were right handed and had normal or corrected-to-normal vision.

\section{Stimuli and apparatus}

The experimental stimuli were identical to those described in Experiment 1, except that four smaller distractors were presented between the 'arms' of the crossing objects, regardless of whether the primes were presented in the background or foreground object.

\section{Procedure}

The experimental procedure was the same as that described in Experiment 1.

\section{Results}

The RTs for the correct responses and the number of errors were analyzed. Two $2 \times 2 \times 2$ repeated measures analyses of variance (ANOVAs) were conducted and included the SOA (23 $\mathrm{ms}$ and $70 \mathrm{~ms}$ ), prime position (foreground and background) and compatibility (compatible and incompatible). The mean RTs and mean error rates for each condition are shown in Figs. 7, 8, 9, and 10.

With respect to the RT, significant difference was not observed between the prime positions $[\mathrm{F}(1,16)=0.42$, $P=0.52]$ or between the SOA conditions $[\mathrm{F}(1,16)=$ $0.75, P=0.40]$. However, significant difference was observed between the compatible and incompatible trials [F $\left.(1,16)=72.80, P<0.001, \eta^{2}=0.82\right]$, showing that the mean RT for the compatible trials $(\mathrm{M}=334 \mathrm{~ms})$ was shorter than that for the incompatible trials $(\mathrm{M}=$ $402 \mathrm{~ms}$ ). The interaction between the prime position and compatibility was not significant $[\mathrm{F}(1,16)=1.32$, $P=0.27]$. Paired $t$-tests were subsequently used to compare the compatible and incompatible trials for each condition separately, and the results confirmed that highly 


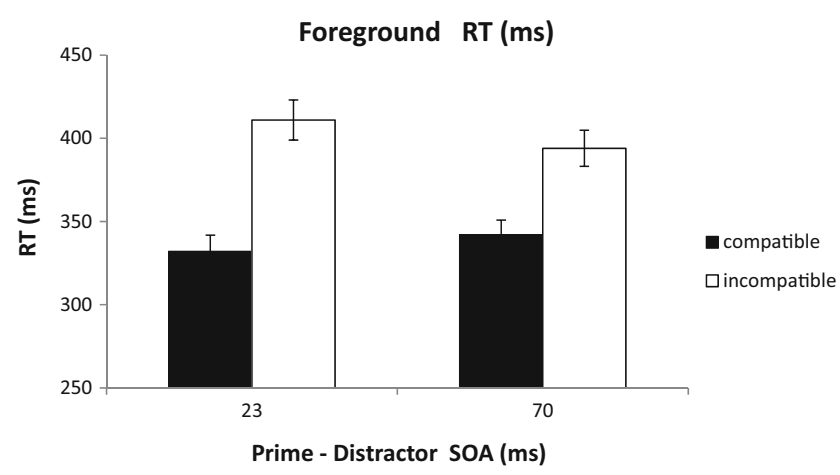

Fig. 7 Mean RTs obtained for the two SOA conditions (23 ms and $70 \mathrm{~ms}$ ) for the compatible and incompatible trials of the foreground condition. Error bars $1 \mathrm{SE}$

significant PCEs were obtained for all conditions $[t$ values $(16)>6.23$ and $P$ values $<0.001]$. Moreover, a comparison of the PCEs between the foreground and background conditions indicated that significant differences did not occur [ $t$ (33) $=0.98, P=0.33]$.

With respect to the error rate, significant difference was not observed between the prime positions $[\mathrm{F}(1,16)=0.04, P=$ $0.84]$ or between the SOA conditions $[\mathrm{F}(1,16)=0.91, P=$ 0.35]. However, significant difference was observed between the compatible and incompatible trials $[\mathrm{F}(1,16)=19.09, P<$ $\left.0.001, \eta^{2}=0.54\right]$, showing that participants made fewer errors in the compatible trials $(\mathrm{M}=1.95 \%)$ than in the incompatible trials $(\mathrm{M}=6.57 \%)$. Paired $t$-tests were subsequently used to compare the compatible and incompatible trials for each condition separately, and the results confirmed that highly significant PCEs were obtained for all conditions $[t$ values $(16)>$ 3.19 and $P$ values $<0.006]$, except for the background condition with the 70-ms SOA $[t(16)=1.54, P=0.14]$. Moreover, a comparison of the PCEs between the foreground and background conditions indicated that significant differences did not occur $[t(33)=1.39, P=0.17]$.

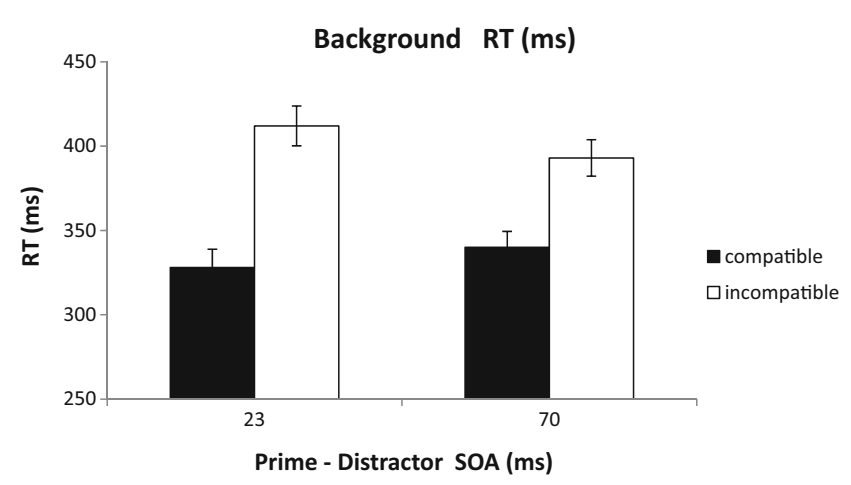

Fig. 8 Mean RTs obtained for the two SOA conditions (23 ms and $70 \mathrm{~ms}$ ) for the compatible and incompatible trials of the background condition. Error bars $1 \mathrm{SE}$

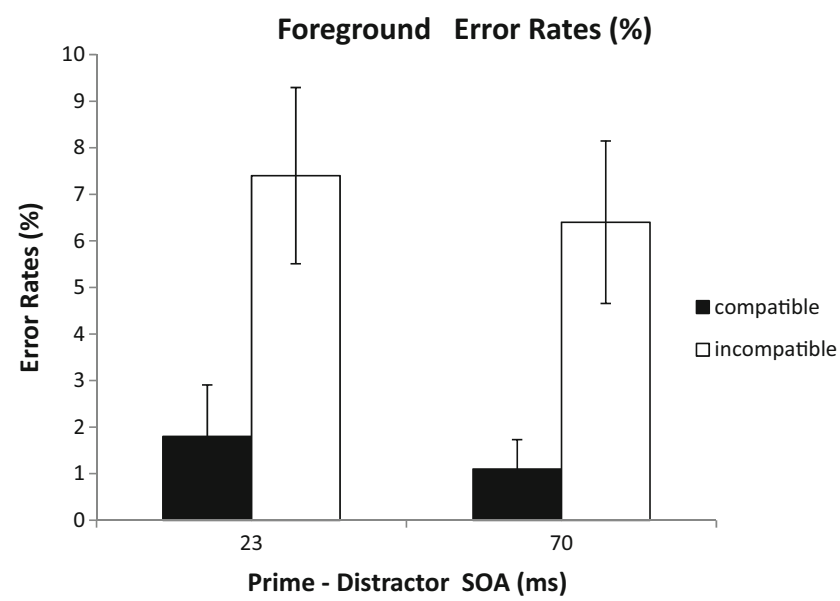

Fig. 9 Mean error rates obtained for the two SOA conditions $(23 \mathrm{~ms}$ and $70 \mathrm{~ms}$ ) for the compatible and incompatible trials of the foreground condition. Error bars $1 \mathrm{SE}$

\section{Discussion}

The aim of the above experiment was to determine whether the prime position modulates the compatibility effects in Experiment 1. PCEs were obtained for all conditions, and significant differences were not observed between the foreground and background conditions. These results indicate that the prime position does not affect the prime activation strength or modulate the compatibility effect, i.e., the results from Experiment 1 were reliable and unaffected by the position of the prime.

\section{General discussion}

\section{Overview of the study}

The aim of the current study was to investigate whether inhibitory processes related to weakly activated priming, which

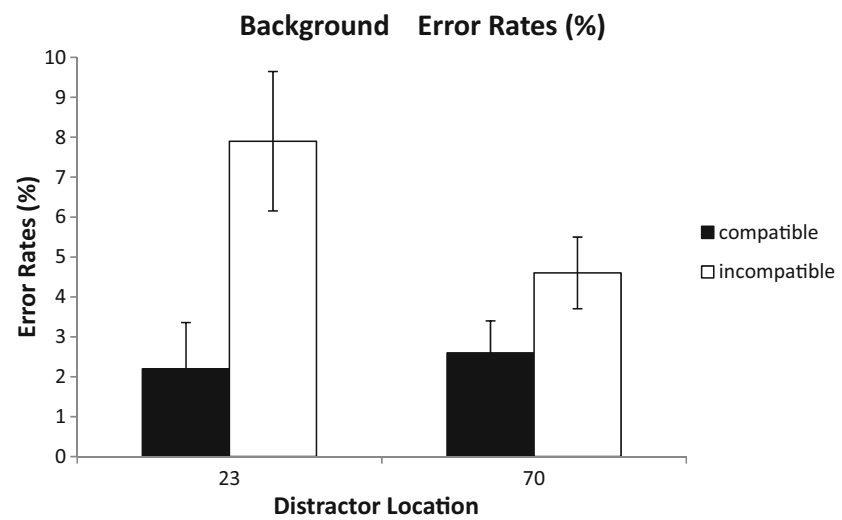

Fig. 10 Mean error rates obtained for the two SOA conditions $(23 \mathrm{~ms}$ and $70 \mathrm{~ms}$ ) for the compatible and incompatible trials of the background condition. Error bars $1 \mathrm{SE}$ 
have been previously assumed to be automatic, depend on the availability of attentional resources. To this end, two experiments were performed using a mixed paradigm involving the NCE and object-based attention. According to the attentional spreading model of object-based attention, the availability of attentional resources is improved by spreading attention across attended objects rather than unattended objects (Chen \& Cave, 2006, 2008; Desimone \& Duncan, 1995; Moore \& Fulton, 2005; Ho, 2011; Richard et al., 2008). Therefore, the availability of attentional resources under the same-object condition will be substantially improved compared with the corresponding availability under the different-object condition. If our hypothesis is correct, inhibition should be substantially weaker under the different-object condition than under the same-object condition. Consequently, we predicted that a significantly greater NCE would be observed under the sameobject condition and a substantially smaller NCE or a PCE would occur under the different-object condition and that the NCE under the same-object condition would be smaller or even reverse with a shorter SOA because the process by which attention spreads within an object is time consuming. The results support these predictions. A significant NCE occurred under the same-object condition when the SOA between the prime and distractor was $70 \mathrm{~ms}$, and PCEs were observed under all other conditions. These results are consistent with the claim that the availability of attentional resources modulates the inhibitory strength related to weakly activated priming. However, the prime position may also affect the results, and the prime activation strength may be stronger in the foreground object than in the background object. In Experiment 2, four smaller distractors were presented between the 'arms' of the crossing objects near the center but always outside of any object-based attentional spreading, regardless of whether the primes were presented in the background or foreground object. This experiment was performed to ensure that the representation strength of the distractors was constant and confirm that the results from Experiment 1 were reliable and unaffected by the prime position. In Experiment 2, PCEs were obtained for all conditions and significant differences were not observed between the foreground and background conditions. Therefore, all of our results are consistent with the claim that the inhibitory processes related to weakly activated priming, which were previously assumed to be automatic, depend on the availability of attentional resources.

\section{Attention and inhibitory processes related to weakly activated priming}

The results of the current study are consistent with the claim that inhibitory processes related to weakly activated priming, which were previously assumed to be automatic, depend on the availability of attentional resources. Although NCEs are highly reliable, and have been observed in many studies involving weakly activated priming (e.g., Bennett et al., 2007; Jaśkowski, 2007, 2008a, b, 2009; Jaśkowski et al., 2008; Jaśkowski \& Verleger, 2007; Lleras \& Enns, 2004, $2005,2006)$, the majority of these studies did not manipulate attentional resources or determine whether inhibitory processes benefited from the focused attention of the targets. The present study suggests that it would likely be premature to interpret the inhibitory processes related to weakly activated priming as indicative of attention-independent processing. Rather, the results are consistent with the claim that inhibitory processes related to weakly activated priming depend on the availability of attentional resources and may vanish under conditions in which attentional resources are less available.

\section{Implications for NCE theories}

The findings of the current study have implications for NCE theories that assume inhibition is triggered by automatic interactions between a prime and distractor (e.g., the $\mathrm{OU}+$ and the MTI hypotheses) (Jaśkowski, 2007, 2008a, b; Jaśkowski \& Verleger, 2007). Our results indicated that the inhibitory processing elicited by the distractor may depend on the availability of attentional resources rather than being a purely automatic process. Specifically, if attentional resources are assigned to the distractor when the distractor is presented in the same object as the prime, then the strength of inhibition elicited by the distractor might increase and vice versa. However, these findings may have no influence on the SI hypothesis because nonmasking distractors were used in the present study. This type of manipulation does not satisfy the prerequisites for the SI hypothesis, which proposes that motor activation by a prime is automatic and produces an inhibition against the initial activation only when the sensory evidence of the prime is immediately removed, i.e., effective backward masking must be used (Eimer \& Schlaghecken, 2002). Therefore, the role of attention in completely unconscious inhibitory processes requires further investigation.

\section{Conclusion}

The present study indicates that inhibitory processes related to weakly activated priming, which have been previously assumed to be automatic, may depend on the availability of attentional resources. Specifically, if attentional resources are assigned to the distractor when the distractor is presented in the same object as the prime, the strength of inhibition elicited by the distractor might increase and reverse the activation elicited by the prime, which could lead to a significant NCE.

Acknowledgments This study was supported by a grant from the Natural Science Foundation of China (31371026) to Yonghui Wang. 


\section{References}

Bennett, J. D., Lleras, A., Oriet, C., \& Enns, J. T. (2007). A negative compatibility effect in priming of emotional faces. Psychonomic Bulletin \& Review, 14, 908-991.

Bowman, H., Eimer, M., \& Schlaghecken, F. (2006). A neural network model of inhibitory processes in subliminal priming. Visual Cognition, 13(4), 401-480.

Boy, F., Clarke, K., \& Sumner, P. (2008). Mask stimulus triggers inhibition in subliminal visuomotor priming. Experimental Brain Research, 190(1), 111-116.

Chen, Z., \& Cave, K. R. (2006). Reinstating object-based attention under positional certainty: The importance of subjective parsing. Perception \& Psychophysics, 68, 992-1003.

Chen, Z., \& Cave, K. R. (2008). Object-based attention with endogenous cuing and positional certainty. Perception \& Psychophysics, 70, 1435-1443.

Chou, W. L., \& Yeh, S. L. (2012). Object-based attention occurs regardless of object awareness. Psychonomic Bulletin \& Review, 19(2), 225-231.

Dehaene, S., Changeux, J. P., Naccache, L., Sackur, J., \& Sergent, C. (2006). Conscious, preconscious, and subliminal processing: A testable taxonomy. Trends in Cognitive Sciences, 10(5), 204-211.

Dehaene, S., Naccache, L., Le Clec'H, G., Koechlin, E., Mueller, M., Dehaene-Lambertz, G., ... Le Bihan D (1998) Imaging unconscious semantic priming. Nature, 395, 597-600.

Desimone, R., \& Duncan, J. (1995). Neural mechanisms of selective visual attention. Annual Review of Neuroscience, 18, 193-222.

Duncan, J., Humphreys, G., \& Ward, R. (1997). Competitive brain activity in visual attention. Current Opinion in Neurobiology, $7(2), 255-261$

Egly, R., Driver, J., \& Rafal, R. D. (1994). Shifting visual attention between objects and locations: Evidence from normal and parietal lesion subjects. Journal of Experimental Psychology: General, 123, 161-177.

Eimer, M., \& Schlaghecken, F. (1998). Effects of masked stimuli on motor activation: Behavioral and electrophysiological evidence. Journal of Experimental Psychology: Human Perception and Performance, 24, 1737-1747.

Eimer, M., \& Schlaghecken, F. (2002). Links between conscious awareness and response inhibition: Evidence from masked priming. Psychonomic Bulletin \& Review, 9(3), 514-520.

Eriksen, C. W., \& St. James, J. D. (1986). Visual attention within and around the field of focal attention: A zoom lens model. Perception \& Psychophysics, 40, 225-240.

Eriksen, C. W., \& Yeh, Y. Y. (1985). Allocation of attention in the visual field. Journal of Experimental Psychology: Human Perception and Performance, 5, 583-597.

Eysenck, M. (1984). Attention and performance limitations. In M. Eysenck (Ed.), A hand-book of cognitive psychology (pp. 49-77). Hillsdale, NJ: Erlbaum.

Ho, M. (2011). Object-based attention: Sensory enhancement or scanning prioritization. Acta Psychologica, 138, 45-51.

Jaśkowski, P. (2007). The effect of nonmasking distractors on the priming of motor responses. Journal of Experimental Psychology: Human Perception and Performance, 33(2), 456-468.

Jaśkowski, P. (2008a). The negative compatibility effect with nonmasking flankers: A case for mask-triggered inhibition hypothesis. Consciousness and Cognition, 17(3), 765-777.

Jaśkowski, P. (2008b). Conscious contributions to subliminal priming. Consciousness and Cognition, 17(1), 72-83.

Jaśkowski, P. (2009). Negative compatibility effect: The objectupdating hypothesis revisited. Experimental Brain Research, 193(1), 157-160.
Jaśkowski, P., Białuńska, A., Tomanek, M., \& Verleger, R. (2008). Maskand distractor-triggered inhibitory processes in the priming of motor responses: An EEG study. Psychophysiology, 45(1), 70-85.

Jaśkowski, P., \& Przekoracka-Krawczyk, A. (2005). On the role of mask structure in subliminal priming. Acta Neurobiologiae Experimentalis, 65(4), 409-417.

Jaśkowski, P., \& Slósarek, M. (2007). How important is a prime's gestalt for subliminal priming? Consciousness and Cognition, 16(2), 485-497.

Jaśkowski, P., \& Verleger, R. (2007). What determines the direction of subliminal priming. Advances in Cognitive Psychology, 3(1-2), 181-192.

Kentridge, R. W., Heywood, C. A., \& Weiskrantz, L. (1999). Attention without awareness in blindsight. Proceedings of the Royal Society of London B: Biological Sciences, 266, 1805-1811.

Kiefer, M., \& Brendel, D. (2006). Attentional modulation of unconscious 'automatic' processes: Evidence from event-related potentials in a masked priming paradigm. Journal of Cognitive Neuroscience, 18(2), 184-198.

Lachter, J., Forster, K. I., \& Ruthruff, E. (2000). Unattended words are not identified. Paper presented at the annual meeting of the Psychonomic Society, New Orleans, LA.

Lamy, D., \& Egeth, H. (2002). Object-based selection: The role of attentional shifts. Perception \& Psychophysics, 64(1), 52-66.

Lingnau, A., \& Vorberg, D. (2005). The time course of response inhibition in masked priming. Perception \& Psychophysics, 67, 545-557.

Lleras, A., \& Enns, J. T. (2004). Negative compatibility or object updating? A cautionary tale of mask-dependent priming. Journal of Experimental Psychology: General, 133, 475-493.

Lleras, A., \& Enns, J. T. (2005). Updating a cautionary tale of masked priming: Reply to Klapp (2005). Journal of Experimental Psychology: General, 134(3), 436-440.

Lleras, A., \& Enns, J. T. (2006). How much like a target can a mask be? Geometric, spatial, and temporal similarity in priming. A reply to Schlaghecken and Eimer (2006). Journal of Experimental Psychology: General, 135, 495-500.

Moore, C. M., \& Fulton, C. (2005). The spreading of attention to hidden portions of occluded surfaces. Psychonomic Bulletin \& Review, 12, 301-306.

Mozer, M. C., \& Vecera, S. P. (2005). Object-based and space-based attention. In L. Itti, G. Rees, \& J. K. Tsotsos (Eds.), Neurobiology of attention (pp. 130-134). New York: Elsevier.

Naccache, L., Blandin, E., \& Dehaene, S. (2002). Unconscious masked priming depends on temporal attention. Psychological Science, 13(5), 416-424.

Neely, J. H., \& Kahan, T. A. (2001). Is semantic activation automatic? A critical re-evaluation. In H. L. Roediger, J. S. Nairne, I. Neath, \& A. M. Surprenant (Eds.), The nature of remembering: Essays in honor of Robert G. Crowder (pp. 69-93). Washington, DC: American Psychological Association.

Ocampo, B., \& Finkbeiner, M. (2013). The negative compatibility effect with relevant masks: A case for automatic motor inhibition. Frontiers in Psychology, 4(1), 822.

Ohman, A., \& Soares, J. J. (1994). "Unconscious anxiety": Phobic responses to masked stimuli. Journal of Abnormal Psychology, 103, 231-240.

Posner, M. I., \& Snyder, C. R. R. (1975). Attention and cognitive control. In R. L. Solso (Ed.), Information processing and cognition (pp. 5585). Hillsdale, NJ: Erlbaum.

Richard, A. M., Lee, H., \& Vecera, S. P. (2008). Attentional spreading in object-based attention. Journal of Experimental Psychology. Human Perception and Performance, 34(4), 842-853.

Schlaghecken, F., \& Eimer, M. (2000). A central/peripheral asymmetry in subliminal priming. Perception \& Psychophysics, 62, 1367-1382. 
Schlaghecken, F., \& Eimer, M. (2002). Motor activation with and without inhibition: Evidence for a threshold mechanism in motor control. Perception \& Psychophysics, 64, 148-162.

Schlaghecken, F., \& Eimer, M. (2004). Masked prime stimuli can bias "free" choices between response alternatives. Psychonomic Bulletin \& Review, 11(3), 463-468.

Schlaghecken, F., \& Eimer, M. (2006). Active masks and active inhibition: A comment on Lleras and Enns (2004) and on Verleger, Jaskowski, Aydemir, van der Lubbe, and Groen (2004). Journal of Experimental Psychology: General, 135(3), 484-494.

Schlaghecken, F., \& Maylor, E. A. (2005). Motor control in old age: Evidence of impaired low-level inhibition. Journals of Gerontology. Series B, Psychological Sciences and Social Sciences, 60, 158-161.

Schlaghecken, F., Rowley, L., Sembi, S., Simmons, R., \& Whitcomb, D. (2007). The negative compatibility effect: A case for self-inhibition. Advances in Cognitive Psychology, 3, 227.

Schneider, W., \& Shiffrin, R. M. (1977). Controlled and automatic human information processing: 1. Detection, search, and attention. Psychological Review, 84, 1-66.

Smith, M. C., Besner, D., \& Miyoshi, H. (1994). New limits to automaticity: Context modulates semantic priming. Journal of Experimental Psychology: Learning, Memory, and Cognition, 20, $104-115$.

Sumner, P., \& Brandwood, T. (2008). Oscillations in motor priming positive rebound follows the inhibitory phase in the masked prime paradigm. Journal of Motor Behavior, 40(6), 484-489.

Sumner, P., Nachev, P., Morris, P., Peters, A. M., Jackson, S. R., Kennard, C., \& Husain, M. (2007). Human medial frontal cortex mediates unconscious inhibition of voluntary action. Neuron, 54, 697-711.
Sumner, P., Tsai, P. C., Yu, K., \& Nachev, P. (2006). Attentional modulation of sensorimotor processes in the absence of perceptual awareness. Proceedings of the National Academy of Sciences of the United States of America, 103(27), 10520-10525.

Vainio, L. (2009). Interrupted object-based updating of reach program leads to a negative compatibility effect. Journal of Motor Behavior, 41, 305-315.

Vainio, L. (2011). Negative stimulus-response compatibility observed with a briefly displayed. Brain and Cognition, 77, 382-390.

Vainio, L., \& Mustonen, T. (2011). Mapping the identity of a viewed hand in the motor system: Evidence from stimulus-response compatibility. Journal of Experimental Psychology: Human Perception and Performance, 37, 207-221.

Verleger, R., Jaśkowski, P., Aydemir, A., Van der Lubbe, R. H. J., \& Groen, M. (2004). Qualitative differences between conscious and non-conscious processing? On negative and positive priming effects induced by masked arrows. Journal of Experimental Psychology: General, 133, 494-515.

Wang, Y., Zhao, J., Liu, P., Wei, L., \& Di, M. (2014). Inhibitory mechanisms in single negative priming from ignored and briefly flashed primes: The key role of the inter-stimulus interval. Consciousness and Cognition, 29, 235-247.

Zemel, R. S., Behrmann, M., Mozer, M., \& Bavelier, D. (2002). Experience-dependent perceptual grouping and object-based attention. Journal of Experimental Psychology: Human Perception \& Performance, 28, 202-217.

Zhao, J., Kong, F., \& Wang, Y. (2013). Attentional spreading in objectbased attention: The roles of target-object integration and target presentation time. Attention, Perception, \& Psychophysics, 75(5), 876-887. 